\title{
Invited Commentary: External tissue expansion and tension relief systems for improved utilisation of the viscoelastic properties of the skin in wound closure
}

mmediate, primary suture closure of wounds is often the optimal solution for soft tissue defect closure because of its simplicity and satisfactory outcome, yet it may be impeded by high tension closure. The customary application of skin grafts, flaps, free tissue transfer or tissue expansion is often associated with relatively more complex surgical reconstructive procedures, significant morbidity, and extended hospitalisation and prolong recovery periods. The concept of tissue expansion is an important method of wound closure based on the utilisation of the viscoelastic properties of the skin by mechanical creep. It provides excellent quality and matching skin texture and color for coverage of soft tissue loss, mainly in the head and neck area. ${ }^{[1,2]}$

Some key disadvantages of the tissue expansion technique is the lengthy period of expansion, their exclusive suitability for application in clean, noninfected areas, their limited application in trauma and following ablative surgery, their tendency to extrude and to get infected and the deformity during the period of expansion. ${ }^{[3,4]}$

External tissue expansion was developed over 20 years ago to harness the viscoelastic properties of the skin by fixing it externally and by applying mechanical creep to stretch it to an extended length; overcoming some of the major shortcomings of internal tissue expansion techniques. ${ }^{[5]}$ The Sure Closure ${ }^{\circledR}$, the Wiseband ${ }^{\circledR}$ and the Dermaclose ${ }^{\circledR}$ - skin stretching systems presented additional alternative for enabling primary wound closure in both trauma and also after ablative surgery. All these devices have an inherent limitation of the size of the defects that can be managed, their invasive nature in the application and the need for several surgical procedures for the closure of moderate to large

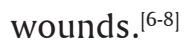

The TopClosure ${ }^{\circledR}$ Tension-Relief System (TRS) is an innovative method that enables the employment of both mechanisms of stress-relaxation and mechanical creep for skin stretching and primary wound closure. Its use has been previously reported to enable the primary closure of medium to large soft tissue defects..$^{[9,10]}$

By stress-relaxation, acute tension is applied to the skin leading to elongation followed by relaxation and retraction to exceed its initial length. Following repeated stress-relaxation, the skin may elongate permanently to a limited extent. There is a practical limitation to the amount of tension that can be applied to the skin by stress-relaxation and the amount of permanent skin stretching that can be achieved due to the concurrent ischemia that is inflicted on the tissue by the applied force. This clinically, limits the use of the stress-relaxation mechanism by suturing techniques as well as by the current external tissue expanders, for immediate primary closure of wounds due to the inflicted ischemia, necrosis and failure of wound closure.

The TopClosure ${ }^{\circledR}$ TRS may also serve as a tensionrelief platform for tension sutures when high tension is indicated for wound closure, to avoid damage to the underlying skin, such as in high-tension closure of large gaps and inelastic skin. This enables the application of acute, intra-operative cycling of stress-relaxation by an ultra-high force. Immediate, primary wound closure can be achieved due to its wide area of attachment to the skin, inflicting $\sim 10^{5}$ less stress to the skin compared with conventional suturing. By applying stressrelaxation, wound closure tension decreases rapidly, allowing immediate, primary closure of relatively large skin defects over a short period [Figure 1]. Delayed primary closure can also be attained using TRS, through gradual pre and post-operative approximation of the skin by mechanical creep, thus serving as external tissue expander. Multiple sets of TRS can be applied perpendicular to the wound longitudinal axis, providing selective local vectors of tension along the wound margins, accommodating for a wide range of wound sizes [Figure 2]. 


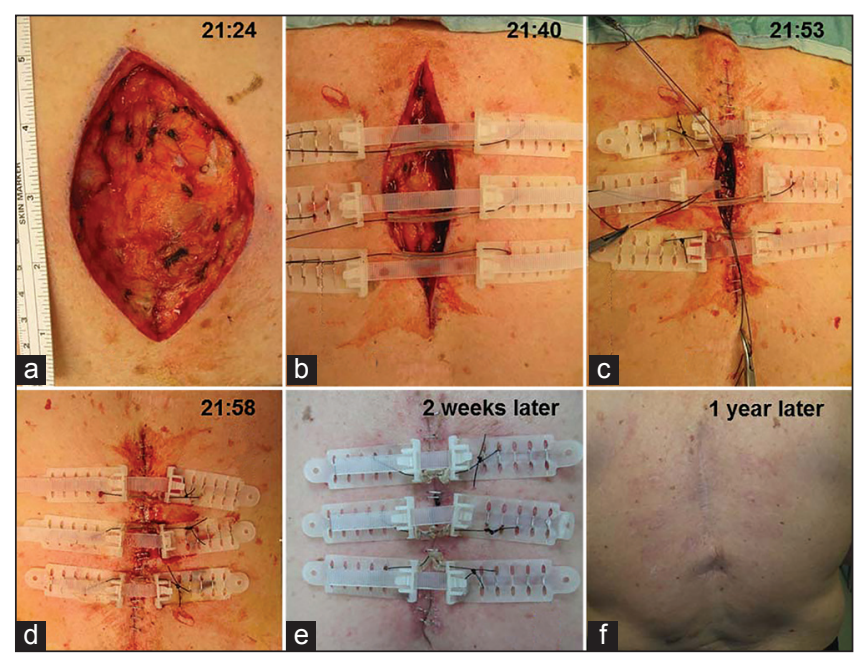

Figure 1: A residual large soft tissue defect $(7 \mathrm{~cm} \times 13 \mathrm{~cm})$ following wide excision of malignant melanoma of the inter-scapular region (a) application of 3 sets of $8 \mathrm{~mm}$ TopClosure ${ }^{\circledR}$ Tension-Relief System to accommodate for tension sutures for stress-relaxation (b) staged closure of wound commencing from low to high tension areas (c) final, high tension wound closure in only $34 \mathrm{~min}$. with no undermining of the skin and no need for a drain (d) full viability of wound edges at 2 weeks (e) 1-year post operation (f)

\section{CONCLUSION}

Tension-Relief System, applied for stress-relaxation and as an external skin stretching device, may provide an additional dimension to our customary methods of reconstructive procedures for wound closure. It can serve as an important tool for immediate and delayed primary closure of a wide range of skin defects of various aetiologies and as a simple alternative for skin grafts, flaps, microvascular free tissue transfer and internal tissue expanders, particularly in patients who are not good candidates for anaesthesia and prolong surgeries.

\section{Moris Topaz}

Department of Plastic Surgery, Hillel Yaffe Medical Centre, Hadera, Israel E-mail: mtopazmd@yahoo.com

\section{REFERENCES}

1. Antonyshyn O, Gruss JS, Zuker R, Mackinnon SE. Tissue expansion in head and neck reconstruction. Plast Reconstr Surg 1988;82:58-68.

2. Bauer BS, Few JW, Chavez CD, Galiano RD. The role of tissue expansion in the management of large congenital pigmented nevi of the forehead in the pediatric patient. Plast Reconstr Surg 2001;107:668-75.

3. Manders EK, Oaks TE, Au VK, Wong RK, Furrey JA, Davis TS, et al. Soft-tissue expansion in the lower extremities. Plast Reconstr Surg 1988;81:208-19.

4. Bozkurt A, Groger A, O'Dey D, Vogeler F, Piatkowski A,

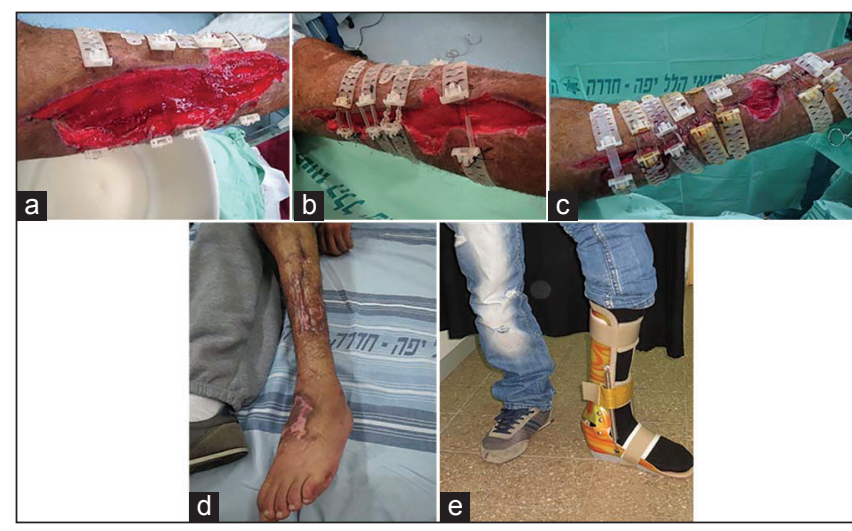

Figure 2: A gun shot injury in the inguinal region with vascular compromise, resulting in compartment syndrome with severe soft tissue necrosis with subsequent huge soft tissue defects of the left leg (a) A $8 \mathrm{~cm} \times 25 \mathrm{~cm}$ defect of the left anterolateral aspect of the leg treated with regulated oxygen-enriched negative pressure-assisted wound system (RO-NPT) (b-d). Application of multiple sets of $8 \mathrm{~mm}$ TopClosure $^{\circledR}$ Tension-Relief System serving for staged closure of the wound by mechanical creep over 7 days (b-d). 3 months following injury with primary closure of wound, salvage of the leg, sustaining functional limb with peroneal splint (e)

Fuchs PCh, et al. Retrospective analysis of tissue expansion in reconstructive burn surgery: Evaluation of complication rates. Burns 2008;34:1113-8.

5. Hirshowitz B, Baum EL, Har-Shai Y. A skin-stretching device for harnessing of the visco-elastic properties of skin. J Plast Reconstr Surg 1994;92:260.

6. Barnea Y, Gur E, Amir A, Leshem D, Zaretski A, Miller E, et al. Delayed primary closure of fasciotomy wounds with Wisebands, a skin and soft tissue-stretch device. Injury 2006;37:561-6.

7. Barnea Y, Gur E, Amir A, Leshem D, Zaretski A, Shafir R, et al. Our experience with Wisebands: A new skin and soft-tissue stretch device. Plast Reconstr Surg 2004;113:862-9.

8. Santiago GF, Bograd B, Basile PL, Howard RT, Fleming M, Valerio IL. Soft tissue injury management with a continuous external tissue expander. Ann Plast Surg 2012;69:418-21.

9. Topaz M, Carmel NN, Silberman A, Li MS, Li YZ. The topclosure ${ }^{\circledR}$ 3S system, for skin stretching and a secure wound closure. Eur J Plast Surg 2012;35:533-43.

10. Topaz M, Carmel NN, Topaz G, Zilinsky I. A substitute for skin grafts, flaps, or internal tissue expanders in scalp defects following tumor ablative surgery. J Drugs Dermatol 2014; 13:48-55.

\begin{tabular}{|l|l|}
\hline \multicolumn{2}{|c|}{ Access this article online } \\
\hline Quick Response Code: & Website: \\
\hline & www.ijps.org \\
\cline { 2 - 2 } & DOI: \\
\hline
\end{tabular}

